\title{
GABA ( $\gamma$-Aminobutyric Acid) Uptake Via the GABA Permease GabP Represses Virulence Gene Expression in Pseudomonas syringae pv. tomato DC3000
}

\author{
S. L. McCraw, ${ }^{1}$ D. H. Park, ${ }^{2}$ R. Jones, ${ }^{1}$ M. A. Bentley, ${ }^{1}$ A. Rico, ${ }^{3}$ R. G. Ratcliffe, ${ }^{1}$ N. J. Kruger, ${ }^{1}$ A. Collmer, ${ }^{4}$ \\ and G. M. Preston' \\ ${ }^{1}$ Department of Plant Sciences, University of Oxford, South Parks Road, Oxford, OX1 3RB, U.K.; ${ }^{2}$ Department of Applied \\ Biology, College of Agriculture and Life Sciences, Kangwon National University, Chuncheon 200-701, Republic of Korea; \\ ${ }^{3}$ Departamento de Didáctica de la 9 Matemática y de las Ciencias Experimentales, Faculty of Education and Sport, University of \\ the Basque Country UPV/EHU, Juan Ibañez de Sto. Domingo 1, 01006 Vitoria-Gasteiz, Spain; and ${ }^{4}$ School of Integrative Plant \\ Science, Section of Plant Pathology and Plant-Microbe Biology, Cornell University, Ithaca, NY 14853, U.S.A.
}

Accepted 15 November 2016.

The nonprotein amino acid $\gamma$-aminobutyric acid (GABA) is the most abundant amino acid in the tomato (Solanum lycopersicum) leaf apoplast and is synthesized by Arabidopsis thaliana in response to infection by the bacterial pathogen Pseudomonas syringae pv. tomato DC3000 (hereafter called DC3000). High levels of exogenous GABA have previously been shown to repress the expression of the type III secretion system (T3SS) in DC3000, resulting in reduced elicitation of the hypersensitive response (HR) in the nonhost plant tobacco (Nicotiana tabacum). This study demonstrates that the GABA permease GabP provides the primary mechanism for GABA uptake by DC3000 and that the $g a b P$ deletion mutant $\triangle g a b P$ is insensitive to GABAmediated repression of T3SS expression. $\triangle \mathrm{AabP}$ displayed an enhanced ability to elicit the HR in young tobacco leaves and in tobacco plants engineered to produce increased levels of GABA, which supports the hypothesis that GABA uptake via GabP acts to regulate T3SS expression in planta. The observation that $P$. syringae can be rendered insensitive to GABA through loss of $g a b P$ but that $g a b P$ is retained by this bacterium suggests that GabP is important for DC3000 in a natural setting, either for nutrition or as a mechanism for regulating gene expression.

$\gamma$-Aminobutyric acid (GABA) is a ubiquitous nonprotein amino acid, which is found across all domains of life. In certain plants, GABA is produced in large quantities in response to abiotic and biotic stresses (Bouche et al. 2003), including the interaction between Pseudomonas syringae pv. tomato DC3000 (hereafter called DC3000) and Arabidopsis thaliana (Ward et al. 2010). Furthermore, GABA is abundant in phloem exudates of oilseed rape (Brassica napus) (Beuvé et al. 2004) and Medicago truncatula (Girousse et al. 1991; Sulieman and Schulze 2010), and it is the most abundant amino acid in leaf

\section{S. L. McCraw and D. H. Park are joint first authors.}

Corresponding author: Gail M. Preston;

E-mail: gail.preston@plants.ox.ac.uk

*The $\boldsymbol{e}$-Xtra logo stands for "electronic extra" and indicates that seven supplementary figures and three supplementary tables are published online. under the CC BY Attribution 4.0 International license. apoplast extracts from tomato (Solanum lycopersicum) and bean (Phaseolus vulgaris) (O'Leary et al. 2016; Rico and Preston 2008; Solomon and Oliver 2001).

Park et al. (2010) established a link between GABA concentrations, both in planta and in vitro, and the ability of DC3000 to express virulence genes by demonstrating that higher concentrations of GABA repress the expression of hrp genes that encode the type III secretion system (T3SS). DC3000 appears to lack glutamate decarboxylase (GadB) (Park et al. 2010) and is, therefore, predicted to be unable to synthesize GABA directly from glutamate, a common route of synthesis in other bacteria, plants, and animals. However, in comparison with other pseudomonads, DC3000 and other $P$. syringae pathovars possess an unusually large number of genes for the conversion of GABA to succinic semialdehyde (three GABA transaminase genes encoded by gabT-1, gabT-2, and gabT-3) and the subsequent conversion of succinic semialdehyde to succinate (three succinic semialdehyde dehydrogenase genes encoded by $g a b D-1, g a b D-2$, and $g a b D-3)$. Park et al. (2010) noted that this apparent excess of GABA metabolism genes in $P$. syringae might imply 'an exceptional ability to convert GABA to succinate.' It has been postulated that the repressive effect that GABA has on virulence gene expression may mean it is important for $P$. syringae cells to degrade GABA rapidly to lessen the repressive effect (Park et al. 2010; Yu et al. 2013).

In order for $P$. syringae to metabolize plant-derived GABA, it must be taken up across the bacterial outer and inner membranes. Multiple mechanisms for GABA uptake have been identified in bacteria, the best characterized of which involves a GABA permease belonging to the APC (amino acid/polyamine/organocation) transporter superfamily, known as GabP (Brechtel et al. 1996; Schneider et al. 2002). The genome of DC3000 contains a putative GABA permease gene (PSPTO_5356) that shares 68\% sequence similarity with $g a b P$ in Escherichia coli K-12 (Brechtel et al. 1996). GABA permeases have also been characterized in Bacillus subtilis (Brechtel and King 1998; Ferson et al. 1996; Zaprasis et al. 2014), Agrobacterium tumefaciens (Planamente et al. 2010), Corynebacterium glutamicum (Zhao et al. 2012), and Rhizobium leguminosarum (Hosie et al. 2002). In E. coli, gabP is found clustered with $g a b T$, $g a b D$, and $g a b C$ (a gene thought to repress the expression of the GABA operon) (Schneider et al. 2002), while in DC3000, PSPTO_5356 is not found in an operon or 
close to any other GABA-related genes. Substrate specificity for GabP in $E$. coli has been reported to be high, with only GABA or GABA analogs able to pass through the permease (Brechtel et al. 1996). However, in B. subtilis GabP has been shown to be a high-affinity transporter for both GABA and $\beta$-alanine and a low-affinity transporter for proline (Zaprasis et al. 2014).

Interestingly, although the genome of DC3000 contains a putative $g a b P$, the genome sequences of many strains of $P$. syringae, including DC3000, display a notable reduction in amino acid permease genes belonging to the Pfam aa_permease family (PF00324), the family within the APC superfamily clan (CL0062) that includes $g a b P$ (Buell et al. 2003). The underlying reason for this reduction is not known, but the fact that the GabP is retained in spite of this reduction suggests it provides an important function for the bacterium.

The expression of $g a b P$ (and other genes involved in GABA metabolism) has been reported to increase on exposure to host plant apoplast in both $P$. syringae pv. syringae B728a and $P$. syringae pv. phaseolicola NPS3121 (Hernández-Morales et al. 2009; Yu et al. 2013). In P. syringae pv. syringae B728a gabP was reported to be moderately upregulated in response to nitrogen limitation in minimal medium (Yu et al. 2013). Chatnaparat et al. (2015a and b) have also recently demonstrated that $P$. syringae strains deficient in the production of ( $\mathrm{p}$ )ppGpp, which coordinates responses to nutrient starvation, show reduced expression of GABA metabolism genes and are impaired in their ability to use GABA as sole carbon or nitrogen source. This implies that uptake of GABA via GabP occurs during plant infection and is affected by nitrogen availability. The alternative sigma factor RpoN $\left(\sigma^{54}\right)$ is required for the transcription of many genes involved in nitrogen uptake and assimilation and virulence in $P$. syringae and other bacteria (Hendrickson et al. 2000a and b; Ramos et al. 2013). Jones et al. (2007) previously demonstrated that an rpoN mutant of Pseudomonas fluorescens is impaired in its ability to assimilate GABA. It is, therefore, reasonable to anticipate that the gabP gene of $P$. syringae may also be regulated by RpoN.

In this study, we investigate the function and regulation of the gabP (PSPTO_5356) gene in DC3000 and its importance for growth and virulence in planta. We describe the construction and characterization of a $g a b P$ deletion mutant of DC3000 and specifically examine the role of gabP in GABA uptake and metabolism, regulation of virulence gene expression, and in the interaction of DC3000 with host and nonhost plants and plants engineered to produce increased levels of GABA.

\section{RESULTS}

gabP is conserved in $P$. syringae and other plant-associated pseudomonads.

GabP ( $g a b P)$ PSPTO_5356 is one of only four predicted amino acid permeases belonging to the Pfam family aa_permease (PF00324), which is retained in DC3000. Its location in the genome is illustrated in Supplementary Fig. S1. Genome comparisons show that the reduction in the size of this family is a common feature of $P$. syringae, with only five aa_permease genes in $P$. syringae pv. phaseolicola $1448 \mathrm{~A}$ and six in $P$. syringae pv. syringae $\mathrm{B} 728 \mathrm{a}$, compared with 21 in $P$. fluorescens $\mathrm{Pf}-5$, P. putida KT2440, and $P$. aeruginosa PAO1.

The majority of Pseudomonas species present in GenBank contain putative gabP genes (Supplementary Fig. S2), with the exception of the $P$. aeruginosa and $P$. mendocina clades. These $g a b P$ genes share close sequence similarity and, where multiple $g a b P$ genes exist within a single genome, as in $P$. putida and $P$. entomophila, are likely to have arisen by gene duplication.

\section{A deletion mutant of PSPTO_5356 is impaired \\ in GABA assimilation.}

Wild-type DC3000 is able to use GABA as both a carbon and a nitrogen source. In contrast, a deletion mutant of DC3000 lacking PSPTO_5356 $(\Delta g a b P)$ is unable to use GABA as a carbon source but is able to use GABA as a nitrogen source in media containing both GABA and glucose (Fig. 1). $\triangle g a b P$ displays an initial growth lag when provided with GABA as a nitrogen source (Fig. 1D) but multiplies to the same density as DC3000 within $36 \mathrm{~h}$ (Fig. 1E). The ability of $\triangle g a b P$ to use GABA as sole carbon source can be partially restored by complementation with pBS46: gabP (Supplementary Fig. S3).

Biolog GN2 MicroPlates were used to compare the ability of DC3000 and $\triangle g a b P$ to metabolize a range of carbon sources in media adjusted to $\mathrm{pH} 5.5$ (apoplastic $\mathrm{pH}$ ) or $\mathrm{pH} 7.0$ (the $\mathrm{pH}$ routinely used for Biolog analyses) (Supplementary Fig. S4). Unsurprisingly, the primary difference in the metabolic phenotype of DC3000 and $\triangle g a b P$ is loss of GABA assimilation, which is evident at both $\mathrm{pH}$ 5.5. and $\mathrm{pH}$ 7.0. $\triangle g a b P$ also shows a reduced ability to metabolize proline and alanylglycine and an increased ability to metabolize citrate but only at $\mathrm{pH}$ 5.5. These results support the identification of PSPTO_5356 as a GABA permease that provides the primary mechanism for GABA uptake in DC3000.

\section{GABA is imported via $g a b P$ and assimilated via the tricarboxylic acid (TCA) cycle.}

The observation that $\triangle g a b P$ is able to grow in the presence of GABA as a nitrogen source but not as a carbon source suggests the presence of an alternative GABA transport system that is active when glucose is available as a carbon source. We investigated this using an isotope dilution approach in which unlabeled GABA was introduced to cells that had been isotopically labeled with $\left[{ }^{13} \mathrm{C}_{6}\right]$ glucose. The loss of ${ }^{13} \mathrm{C}$-labeled carbon from amino acids incorporated into protein was monitored over time (Fig. 2; Supplementary Fig. S5).

In media supplemented with both GABA and $\left[{ }^{13} \mathrm{C}_{6}\right]$ glucose, the amino acid labeling patterns observed in DC3000 are consistent with co-metabolism of glucose and GABA, with decreased labeling in amino acids derived from TCA cycle intermediates and continued incorporation of label into amino acids derived from sugar phosphates and three-carbon phosphate esters. For example, little reduction can be seen in the labeling of serine and histidine, derived from triose and pentose phosphates, but labeling is rapidly reduced in glutamate and aspartate, derived from oxoglutarate and oxaloacetate, respectively. In media containing GABA as sole carbon source, all amino acids show a substantial reduction in labeling within $24 \mathrm{~h}$ in DC3000, with a more rapid decrease being observed in amino acids derived from TCA-cycle intermediates (aspartate, threonine, glutamate, lysine, and arginine). In contrast, after $24 \mathrm{~h}, \Delta \mathrm{gabP}$ cells show no decrease in labeled carbon in the measured amino acids in either the GABA or GABA $+\mathrm{NH}_{4}^{+}$treatments (Fig. 2), consistent with the inability of $\triangle g a b P$ to grow in these treatments (Fig. 1).

$\triangle g a b P$ only shows a substantial decrease in labeling of TCA cycle-derived amino acids in the GABA and $\left[{ }^{13} \mathrm{C}_{6}\right]$ glucose treatment after $24 \mathrm{~h}$ (Fig. 2). The decrease in labeling in TCA cycle-derived amino acids observed in this treatment suggests that both DC3000 and $\triangle g a b P$ assimilate GABA intracellularly via the action of GABA transaminase and succinic semialdehyde dehydrogenase, irrespective of whether it is transported by GabP or by an alternative transport mechanism. However, the long delay before decreased labeling can be detected in $\triangle g a b P$ relative to DC3000 demonstrates that, although an alternative transport mechanism capable of transporting GABA exists in DC3000, GabP provides the primary route for GABA uptake. 

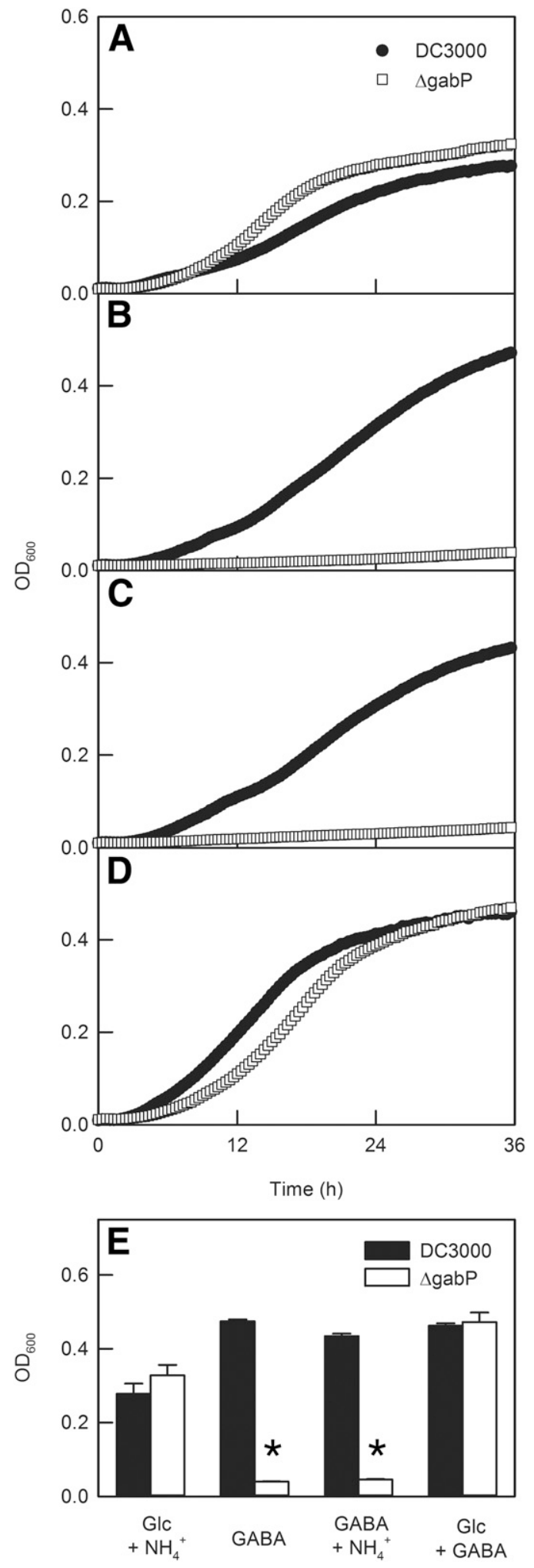

Fig. 1. Comparison of the ability of Pseudomonas syringae pv. tomato DC3000 and $\triangle \mathrm{gabP}$ to use $\gamma$-aminobutyric acid (GABA) as a carbon source, a nitrogen source, and as a carbon and nitrogen source. A to $\mathbf{D}$, Cultures of DC 3000 (black circle) and $\triangle g a b P$ (white square) were grown in M9-glucose medium (A) or media in which GABA replaced glucose and ammonium chloride (B), glucose (C), or ammonium chloride (D). Representative data for individual cultures from four independent growth studies are presented. E, Comparison of cell density of DC3000 and $\triangle g a b P$ across the different treatments $36 \mathrm{~h}$ after subculture. Values are the mean \pm standard deviation of three independent replicates. An asterisk (*) indicates a value that is significantly different from DC3000 grown in the same medium (Student's $t$-test; $P<0.01$ ).
PSPTO_5356 expression is induced

by GABA and regulated by RpoN.

Wild-type DC3000 displays a 15-fold increase in expression of $g a b P$ in media containing GABA as a carbon source (Supplementary Fig. S6), but an rpoN mutant (A. Chatterjee, personal gift) is unable to grow in this environment (data not shown) and displays a fivefold decrease in $g a b P$ expression. It, therefore, seems likely that $g a b P$ is up-regulated in the presence of GABA via an RpoN-dependent regulatory mechanism. A sequence conforming to the $-24 /-12$ consensus motif (GG-10bp-GC) recognized by RpoN (Studholme et al. 2000) is located 81 bp upstream of the start codon of PSPTO_5356 (GGCGTAATTCTTGC), which suggests that RpoN may directly regulate gabP expression.

\section{$\triangle g a b P$ is not impaired in growth}

in planta or in extracted tomato leaf apoplast.

GABA is the most abundant amino acid in the tomato leaf apoplast, and increases in abundance in A. thaliana plants inoculated with $P$. syringae (Rico and Preston 2008; Ward et al. 2010). However, the degree and severity of disease symptoms caused by DC3000 and $\triangle g a b P$ in tomato are indistinguishable when bacteria are introduced by infiltration at $10^{4} \mathrm{CFU} / \mathrm{ml}$ (data not shown) or dip-inoculation at $10^{4}$ or $10^{6}$ CFU/ml (Fig. 3A; data not shown). $\triangle$ gabP also shows no significant difference from DC3000 in its ability to colonize tomato leaves or tomato leaf apoplastic washing fluid (AWF) or in its ability to colonize A. thaliana (Ler) and the GABAaccumulating line pop 2-1 (Palanivelu et al. 2003), which lacks GABA transaminase (Supplementary Fig. S7).

\section{$\triangle g a b P$ is able to deplete}

the same apoplastic components as DC3000.

The observation that $\triangle g a b P$ shows no difference from DC3000 in its ability to colonize GABA-rich plants or grow in apoplast extracts suggests that DC3000 does not use GABA as a primary source of carbon or nitrogen in these environments. To examine whether DC3000 takes up GABA during growth in the plant apoplast and to investigate whether $\triangle g a b P$ is altered in its ability to absorb GABA or other metabolites in an apoplastic environment, we performed a metabolic footprinting experiment in which $\triangle g a b P$ and DC3000 were grown in tomato leaf AWF, which was then profiled using proton nuclear magnetic resonance $\left({ }^{1} \mathrm{H}-\mathrm{NMR}\right)$ (Fig. 4).

Both DC3000 and $\triangle g a b P$ preferentially deplete the same metabolites following inoculation into AWF, including amino acids such as asparagine, aspartate, glutamine, and glutamate. Both strains fail to deplete betaine, inositol, serine, and threonine. However, at $8 \mathrm{~h}$, there is a significant difference between the two strains in GABA depletion, with a reduction in the GABA content of extracts incubated with DC3000 but not those incubated with $\Delta g a b P$ (Fig. $4 \mathrm{~A}$ ). This confirms that GabP is the primary transporter for GABA uptake but shows that GABA is only taken up by GabP once preferred nutrient sources such as glutamate and aspartate have been depleted. By $24 \mathrm{~h}, \Delta g a b P$ depletes GABA to the same degree as DC3000, which suggests that the secondary transport mechanism identified in the isotope dilution analysis (Fig. 2) can be used for inefficient or delayed uptake of GABA in $\triangle g a b P$ over a prolonged incubation period. The only other statistically significant difference between the two strains is increased uptake of the nicotinatederived secondary metabolite trigonelline ( $N$-methyl nicotinamide) (Ashihara et al. 2015; Minorsky 2002) by $\Delta g a b P$. These results provide compelling evidence that, despite its abundance in the tomato apoplast, GABA is a less-favored carbon and nitrogen source for DC3000, which preferentially assimilates other abundant amino acids, such as glutamate and aspartate. 
$\triangle g a b P$ elicits an increased hypersensitive response (HR) in tobacco plants that overproduce GABA.

It was previously reported that a GABA transaminasedeficient mutant of DC3000 ( $\triangle$ gabT2/T3/T1) showed a reduced ability to elicit the HR in tobacco (Park et al. 2010), which was attributed to repression of T3SS expression by GABA. It was, therefore, logical to examine whether $\triangle g a b P$ displayed an altered ability to elicit the HR. The ability of $\triangle g a b P$ to elicit the HR is indistinguishable from DC3000 in mature wild-type tobacco ('Xanthi') leaves. However, in young leaves, $\triangle g a b P$ is able to
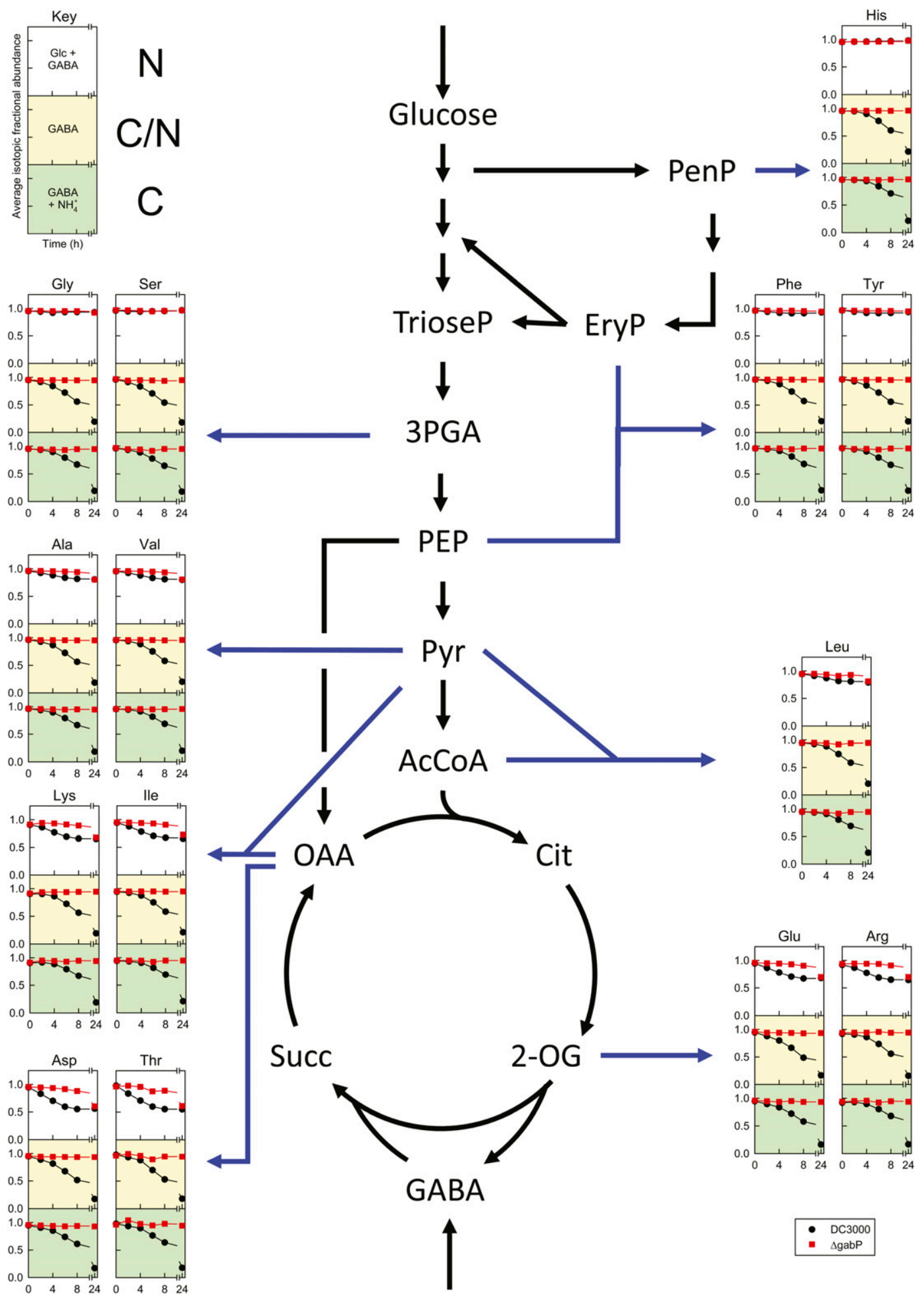

GABA
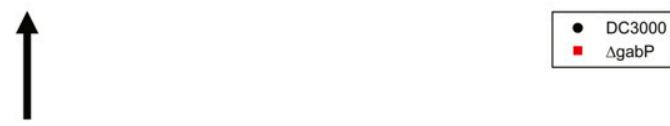

Fig. 2. Isotope dilution analysis reveals an alternative mechanism for transporting $\gamma$-aminobutyric acid (GABA) into Pseudomonas syringae pv. tomato DC3000 in the absence of $g a b P$. Cultures of DC3000 (circle) and $\triangle g a b P$ (square) were grown in $\left[{ }^{13} \mathrm{C}_{6}\right]$ glucose to label cellular protein prior to incubation with unlabeled GABA, either in combination with ${ }^{13} \mathrm{C}_{6}$ glucose (upper panels), alone (middle panels), or with ammonium chloride (lower panels). Under these conditions, GABA provides the sole source of nitrogen $(\mathrm{N})$, both carbon and nitrogen $(\mathrm{C} / \mathrm{N})$, or carbon $(\mathrm{C})$, respectively. The mean ${ }^{13} \mathrm{C}$ fractional abundance of amino acids obtained by hydrolysis of proteins extracted from cells sampled at intervals after transfer to unlabeled media was determined. Data show the mean of values obtained from three independent replicates for which the standard deviation is typically less than 5\% and is obscured by the symbol. The metabolic map indicates the precursor for synthesis of each amino acid. 
elicit the HR at lower densities than wild-type DC3000 (Fig. 3B), which may reflect age-dependent differences in leaf apoplast composition or plant defense signaling processes (Allan and Shelp 2006; Masclaux et al. 2000).

To investigate whether the level of GABA present in plant tissues affects HR elicitation, we examined the interaction of DC3000 and $\triangle g a b P$ with tobacco plants engineered to overproduce GABA through overexpression of a truncated version of glutamate decarboxylase, which lacks the autoinhibitory calmodulin-binding domain (GAD $\Delta \mathrm{C} 1)$ (McLean et al. 2003). AWF composition analyses demonstrate that GABA accounts for $61 \%$ percent of total amino acids in GAD $\triangle \mathrm{C} 1 \mathrm{AWF}$, in comparison with $36 \%$ of total amino acids in AWF from wild-type leaves. $\triangle g a b P$ elicits visible necrosis at

A
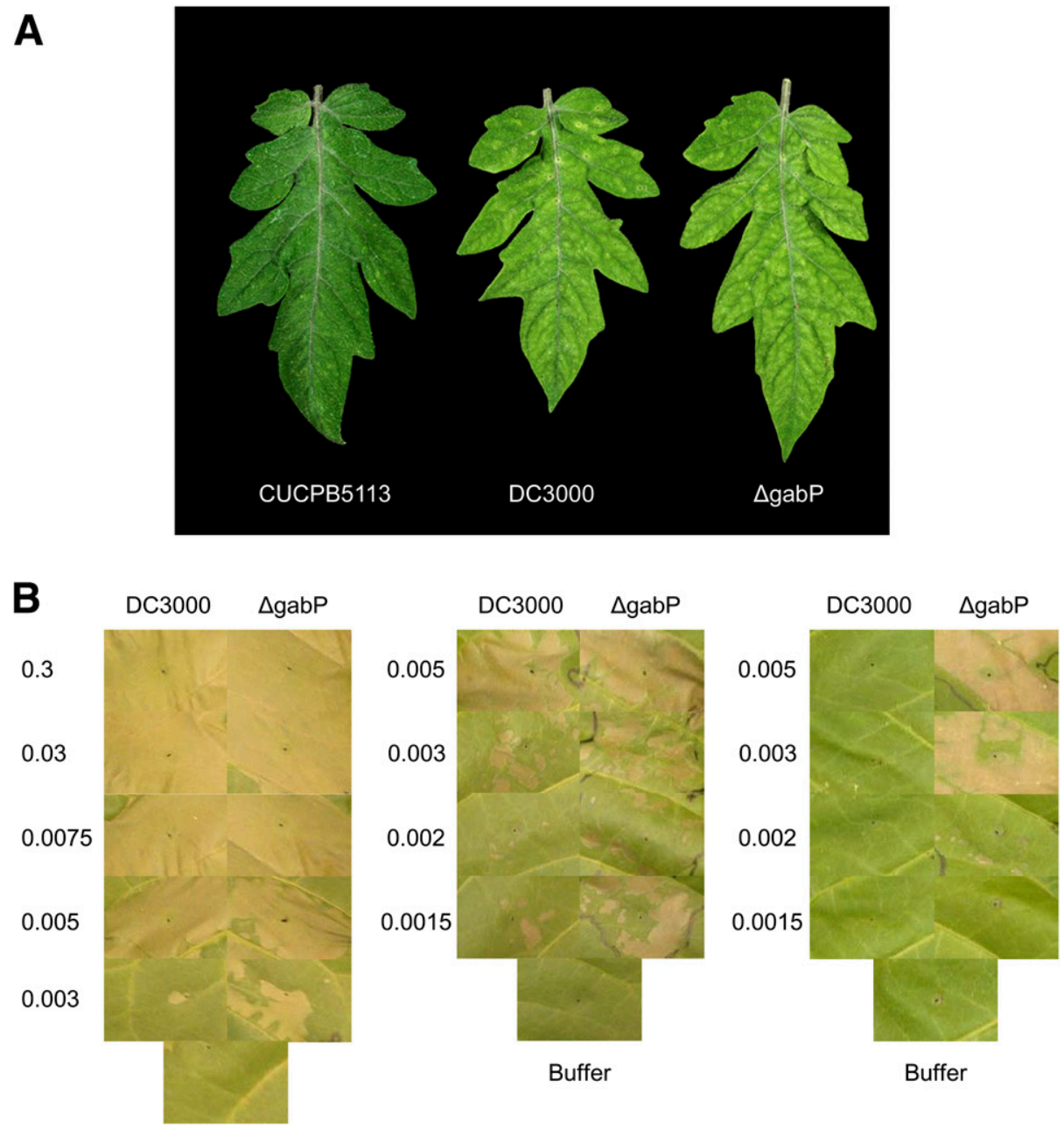

Buffer

Lower leaves

Upper leaves
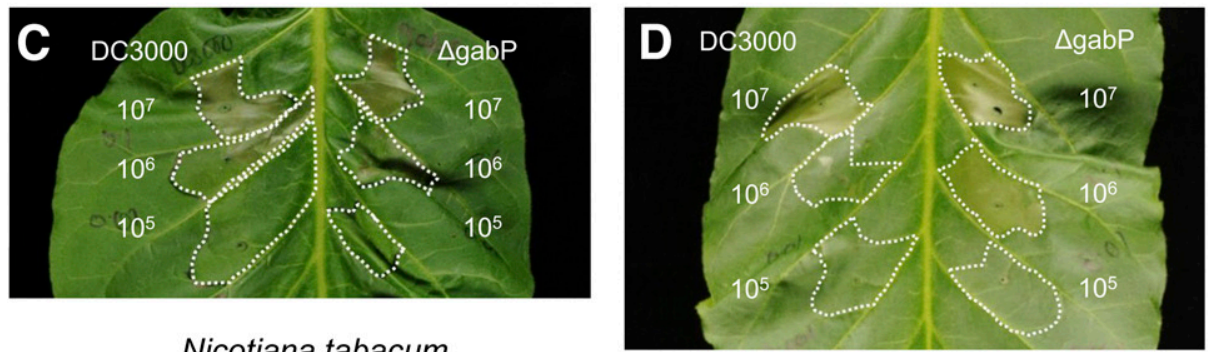

Nicotiana tabacum

cv Delgold

GAD $\triangle \mathrm{C} 1$

Fig. 3. Comparison of symptoms elicited by Pseudomonas syringae pv. tomato DC3000 and $\Delta$ gabP in tomato (host) and tobacco (nonhost) leaves. A, Disease symptoms in tomato (Solanum lycopersicum cv. Moneymaker). Leaves were dipped in bacterial suspensions adjusted to $10^{4} \mathrm{CFU} / \mathrm{ml}$ in $10 \mathrm{mM} \mathrm{MgCl}_{2}$ supplemented with $0.02 \%$ Silwet L-77. Symptoms were photographed 7 days postinoculation. The nonpathogenic type III secretion mutant DC3000 hrcQbRSTU:: $\Omega \mathrm{Sp}^{\mathrm{r}} / \mathrm{Sm}^{\mathrm{R}}$ (CUCPB5113) (Badel et al. 2006) is shown as a negative control. B, Hypersensitive response (HR) elicitation in tobacco (Nicotiana tabacum cv. Xanthi) leaves of varying age. Bacteria were suspended in $10 \mathrm{mM} \mathrm{MgCl}_{2}$ and were diluted to obtain the inoculum densities (optical density at 600 $\mathrm{nm}$ ) shown. Suspensions were inoculated into leaves, which were photographed $24 \mathrm{~h}$ postinoculation. $\mathbf{C}$ and $\mathbf{D}$, The impact of increased $\gamma$-aminobutyric acid (GABA) content on HR elicitation in tobacco. Tobacco (cv. Delgold) leaves were inoculated with bacteria suspended in $10 \mathrm{mM} \mathrm{MgCl}_{2}$ at densities between $10^{5}$ and $10^{7}$ cells/ml. HR elicitation was assessed in wild-type plants $(\mathrm{C})$ and in a transgenic line (GAD $\left.\Delta \mathrm{C} 1\right)$ that exhibits increased GABA content (D). Symptoms were photographed $24 \mathrm{~h}$ postinoculation. 
lower cell densities than wild-type DC3000 in GAD $\Delta$ C 1 plants (Fig. 3C and D).

\section{$\Delta g a b P$ is insensitive to $h r p$ repression by GABA.}

As GABA has been shown to repress the expression of the $h r p$ genes encoding the $P$. syringae T3SS, which delivers effectors that elicit the HR (Park et al. 2010), we speculated that the increased ability of $\triangle g a b P$ to elicit the HR in GABA-rich plant tissues resulted from its ability to continue to express the T3SS at a high level in the presence of exogenous GABA due to lack of GABA uptake. We introduced a luminescent reporter plasmid, pBS63, containing a transcriptional fusion of the $h r p L$ promoter to the lux operon (provided by B. Swingle, United States Department of Agriculture-Agricultural Research Service [USDA-ARS]) into DC3000 and $\triangle g a b P$. The luminescence and optical density (OD) of the reporter strains was monitored in hrpinducing M9-fructose medium, in which glucose is replaced with fructose (Huynh et al. 1989; Rahme et al. 1992) and the $\mathrm{pH}$ is adjusted to 5.5 to mimic apoplastic $\mathrm{pH}$ (Brencic and Winans 2005). DC3000 and $\triangle g a b P$ display similar growth and luminescence in M9-fructose but, as predicted, $\triangle g a b P$ does not exhibit the GABA-dependent repression of $h r p$ expression shown by DC3000 (Fig. 5A and B). Quantitative reverse transcriptionpolymerase chain reaction (qRT-PCR) analyses confirm that the expression of both $h r p L$ and the HrpL-regulated effector gene avrE are repressed by GABA in DC3000 and that this repression is alleviated in $\triangle g a b P$ (Fig. 5C).

\section{DISCUSSION}

PSPTO_5356 is the primary GABA permease in DC3000 and is regulated by RpoN.

The results reported here demonstrate that PSPTO_5356 $(g a b P)$ provides the primary route by which DC3000 takes up
GABA from its environment, including the leaf apoplast. It also offers evidence that DC3000 gabP is part of a suite of RpoNdependent genes that are regulated in response to physiological stimuli associated with carbon and nitrogen availability in the plant environment and which include the positive activator of hrp expression $h r p L$ (Yu et al. 2014). $h r p L$ is regulated by HrpR and $\mathrm{HrpS}$, which belong to the $\mathrm{NtrC}$ (nitrogen regulatory) family of two-component regulators that act in conjunction with RpoN to regulate gene expression (Tang et al. 2006). The identity of the $\mathrm{NtrC}$ family regulator responsible for regulation of gabP in $P$. syringae remains to be determined, but a possible candidate is $\mathrm{CbrB}$, as both an $r p o N$ mutant and $c b r B$ mutant of the plant growth-promoting strain $P$. fluorescens SBW25 lose the ability to assimilate GABA as a carbon source, while an $n t r C$-deficient mutant is unaffected (Jones et al. 2007; Zhang and Rainey 2008).

The regulation and properties of the GabP permease described here are very similar to those reported for the GabP permease of B. subtilis, in which gabP transcription is induced in nitrogenlimiting conditions, and controlled by the main nitrogen regulatory protein of B. subtilis, TnrA (Ferson et al. 1996). $\mathrm{GabP}$ is the primary, high-affinity transporter for GABA in both $P$. syringae and $B$. subtilis, although both possess transporters that enable a low level of GABA uptake in a gabP mutant background (Zaprasis et al. 2014). The similarities in the regulation and function of GabP in these two unrelated bacteria suggest that GabP may play a physiologically analogous role in GABA uptake and metabolism in a range of plant- and soil-associated bacteria.

Interestingly, although this study provides strong support for a role for GabP as the primary GABA permease in DC3000, it is possible that GabP may also act to import other plant metabolites. In $B$. subtilis GabP has been reported to be a high-affinity transporter for both GABA and $\beta$-alanine and a low-affinity transporter for proline (Zaprasis et al. 2014), while GABA permeases in Saccharomyces cerevisiae and A. thaliana have been reported to

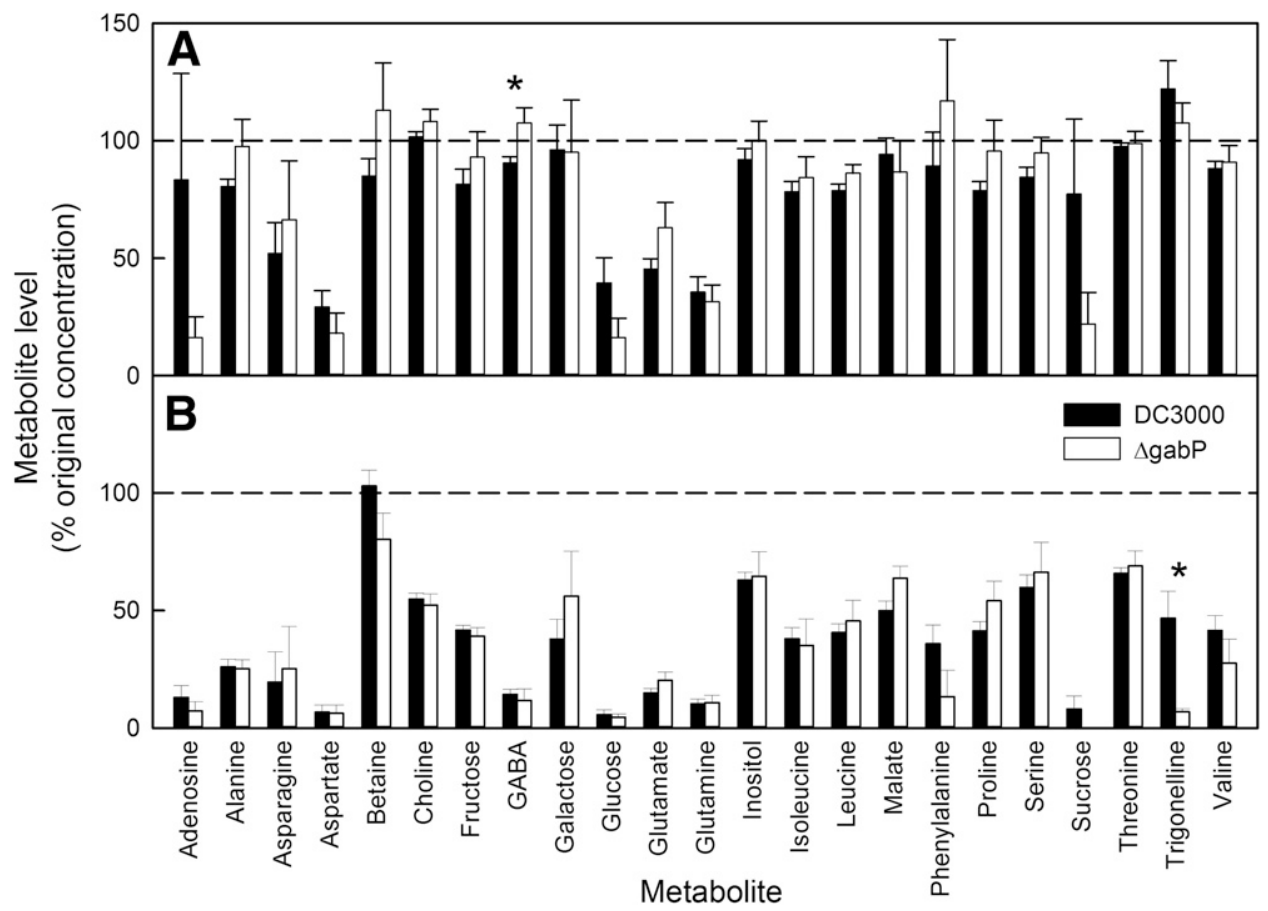

Fig. 4. Depletion of tomato leaf apoplastic metabolites by Pseudomonas syringae pv. tomato DC3000 and $\Delta g a b P$. Tomato leaf apoplast washing fluid was inoculated with DC3000 (filled column) and $\triangle g a b P$ (open column) and the metabolic composition of the culture medium was analyzed by proton nuclear magnetic resonance $\mathbf{A}, 8$ and $\mathbf{B}, 24 \mathrm{~h}$ after inoculation. Spectra were normalized to total spectral intensity and the abundance of each metabolite was expressed relative to the mean of that measured in the original apoplast extract. Each value is the mean \pm standard deviation from three independent replicates. Dashed lines indicate the relative metabolite concentration in the original apoplast extract, for reference. An asterisk (*) indicates values that differ significantly between DC3000 and $\triangle g a b P$ (Student's $t$-test; $P<0.01$ ). 
transport, respectively, both GABA and proline (Jauniaux et al. 1987) or GABA, proline, and glycine betaine (Grallath et al. 2005). Although proline is a relatively poor carbon source for DC3000 (Rico and Preston 2008), we observed an appreciable reduction in proline utilization by $\triangle g a b P$ in Biolog analyses, although only at $\mathrm{pH} 5.5$. GabP may, therefore, also contribute to the uptake of additional plant metabolites, although it seems unlikely that GabP is a major transporter for glycine betaine in DC3000 as OpuC (PSPTO_4575-4578) has been identified as the primary transporter for this compound (Chen and Beattie 2007).

Why does DC3000 retain a gene that potentially reduces its ability to suppress host defense responses?

The retention of $g a b P$ in DC3000 along with the repressive effect of GABA on virulence gene expression in DC3000
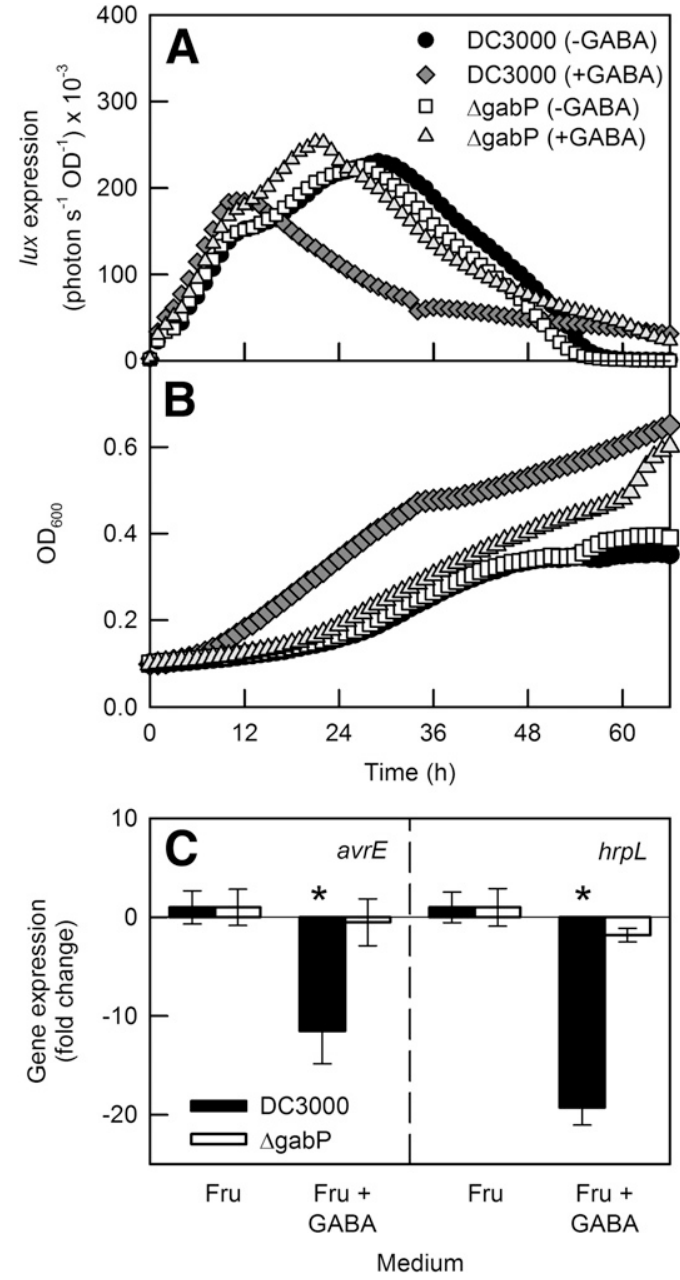

Fig. 5. $\triangle g a b P$ is insensitive to $\gamma$-aminobutyric acid (GABA)-mediated inhibition of virulence gene expression. The effect of GABA on virulence gene expression in Pseudomonas syringae pv. tomato DC3000 and $\triangle g a b P$ was assessed using a luminescent reporter fusion to $h r p L$ (pBS63) and through quantitative reverse transcription-polymerase chain reaction (qRTPCR) analysis of $h r p L$ and $a v r E$. A, Normalized luminescence and $\mathbf{B}$, optical density at $600 \mathrm{~nm}\left(\mathrm{OD}_{600}\right)$ measurements for DC3000 (pBS63) (circle, diamond) and $\triangle g a b P$ (pBS63) (square, triangle) in M9-fructose (circle, square) and M9-fructose supplemented with $5 \mathrm{mM} \mathrm{GABA}$ (diamond, triangle). Data shown are the mean \pm standard deviation (SD) of four replicates. C, qRT-PCR analysis of $a v r E$ and $h r p L$ expression in M9-fructose (Fru) and M9-fructose supplemented with $5 \mathrm{mM} \mathrm{GABA}$ (Fru + GABA). Cells were harvested to extract RNA $6 \mathrm{~h}$ after inoculation. groEL and rpoD were used as reference genes. Data shown are the mean \pm SD of three replicates. An asterisk $(*)$ indicates an expression level significantly different from that of the same strain grown in M9-fructose medium (Student's $t$-test $P<0.01)$ presents an intriguing paradox. GABA potentially presents an abundant source of carbon and nitrogen for $P$. syringae pv. tomato, and growth experiments demonstrate DC3000 is capable of rapid growth using GABA as a carbon or nitrogen source. However, $\triangle g a b P$ was not impaired in growth in susceptible host plants compared with DC3000, and GABA is not depleted by DC3000 to a significant degree until $8 \mathrm{~h}$ postinoculation in tomato apoplast extracts, during which DC3000 preferentially depletes glucose, glutamate, glutamine, and aspartate. This suggests that $\mathrm{GabP}$ is not primarily used as a nutrient transporter when other preferred nutrients are available.

hrp genes involved in T3SS synthesis are known to be induced rapidly upon introduction of $P$. syringae into the plant environment (as early as $1 \mathrm{~h}$ postinoculation), and continued high level induction has been observed for over $6 \mathrm{~h}$ (Brencic and Winans 2005; Ortiz-Martín et al. 2010). However, hrp expression has been observed to drop within $24 \mathrm{~h}$ after inoculation, and it has been speculated that this corresponds to a change in apoplast composition that results in suppression of hrp expression (Thwaites et al. 2004). The results presented here and previous results showing that the accumulation of intracellular GABA represses hrp expression in P. syringae (Park et al. 2010) suggest two mechanisms that could contribute to this pattern of hrp expression.

First, the delayed GABA depletion observed in metabolite footprinting experiments suggests that gabP may initially be repressed or GabP post-translationally inactivated following inoculation, enabling $h r p$ genes to be expressed at high levels, even in plants such as N. tabacum and Solanum lycopersicum, in which GABA can be the most abundant amino acid in the leaf apoplast (Rico and Preston 2008). In this respect, it is notable that we observed rapid induction of $h r p L$ expression in DC3000 in $h r p$-inducing conditions, even in the presence of high concentrations of GABA, with subsequent GabP-dependent repression of hrp expression in DC3000 after prolonged incubation. However, $g a b P$ and other genes associated with GABA metabolism are known to be upregulated within $48 \mathrm{~h}$ after infection of plants by $P$. syringae (Yu et al. 2013). Therefore, it is possible that GabP-mediated GABA uptake contributes to a reduction in T3SS expression once infection has been initiated, thereby reducing the cost of T3SS expression in a susceptible host or attenuating the induction of plant defenses in hosts in which delivery of T3SSsecreted effectors results in elicitation of effector-triggered immunity (ETI) and a concomitant increase in apoplastic GABA (O'Leary et al. 2016), as discussed below.

It has also been suggested that GabP, in conjunction with GABA transaminase ( $g a b T$ ), can contribute to the maintenance of intracellular glutamate levels under conditions of starvation and osmotic stress (Metzner et al. 2004). DC3000 exhibits physiological responses characteristic of adaptation to osmotic stress during apoplast colonization and is known to accumulate glutamate as a compatible solute (Freeman et al. 2010, 2013). ETI also creates an environment that imposes increased osmotic stress (Wright and Beattie 2004). A role for GABA uptake in maintaining the intracellular glutamate pool is consistent with the observation that GABA is depleted from apoplast extracts only once preferred amino acids such as glutamate and glutamine have become substantially depleted.

\section{Could GABA act as a signal}

\section{of the onset of plant defense responses?}

The induction of plant defenses is known to be directly associated with increased concentrations of cytoplasmic and apoplastic GABA, for example, during disease and pathogenassociated molecular pattern-triggered immunity in A. thaliana (Ward et al. 2010), ETI in N. tabacum (Gupta et al. 2013), and disease and ETI in Phaseolus vulgaris (O'Leary et al. 2016). In 
plants GABA is mainly produced by an irreversible reaction catalyzed by the cytosolic $\mathrm{Ca}^{2+} /$ calmodulin $(\mathrm{CaM})$-dependent enzyme glutamate decarboxylase (GAD, EC 4.1.1.15), which is activated by either or both $\mathrm{Ca}^{2+}$ signaling or acidification of the cytosol during ETI. Thus, GABA accumulates to high levels in the leaf apoplast, following the onset of cell death and the loss of cell membrane integrity associated with ETI, which occurs 6 to $8 \mathrm{~h}$ after inoculation (O'Leary et al. 2016). Therefore, the accumulation of apoplastic GABA and its uptake via GabP could contribute to downregulation of T3SS expression in planta.

A role for GABA uptake in regulation of $h r p$ expression and in mitigation of plant defenses is consistent with the enhanced elicitation of the HR by $\triangle g a b P$ in tobacco leaves. It should be noted that this assay has been found to be significantly more sensitive to quantitative variation in T3SS function than in planta growth assays (Kvitko et al. 2007). The phenotype of $\triangle g a b P$ in planta is similar to that reported for a mutant of $P$. syringae pv. phaseolicola lacking the negative regulator of T3SS expression HrpV, in which derepression of hrp expression was associated with increased HR elicitation in the nonhost plant tobacco but had no discernable effect on growth in the host plant bean (Ortiz-Martín et al. 2010). Increased HR elicitation has also been reported for $P$. syringae strains lacking Lon protease, which acts to degrade the positive regulator of $h r p$ expression HrpR and T3SS-secreted effectors (Ortiz-Martín et al. 2010; Yang et al. 2011). As T3SS function is known to be regulated at multiple levels, including $h r p$ gene transcription, degradation of $h r p$ regulatory proteins and effectors, and post-translational regulation of T3SS assembly and effector delivery (Jovanovic et al. 2014; Ortiz-Martín et al. 2010; Wei and Collmer 2012), it will be of interest in future work to determine which mechanisms contribute to GabP and GABA-mediated regulation of T3SS function and $\mathrm{HR}$ elicitation.

\section{Loss of GabP leads to increased uptake of trigonelline and reveals an alternative mechanism for GABA uptake in DC3000.}

In addition to repressing hrp expression, GABA uptake via gabP may also affect the activity of other metabolite uptake mechanisms in $P$. syringae. Intriguingly, the only significant difference between $\triangle g a b P$ and DC3000 in apoplast metabolite footprinting experiments, other than a reduction in GABA uptake by $\triangle g a b P$, was increased depletion of the nicotinate-derived secondary metabolite trigonelline by $\triangle g a b P$ after $24 \mathrm{~h}$. Trigonelline has previously been identified as a competitive inhibitor of GABA transporters and receptors (Breitkreuz et al. 1999; Hossain et al. 2003), indicating a potential overlap in binding specificity. Thus, this phenotype could be linked to derepression of trigonelline uptake and assimilation mechanisms or to induction of a transporter capable of transporting both GABA and trigonelline, but this remains to be investigated.

In fact, DC3000 appears to possess an alternative GABA transport mechanism, which is active when bacteria are grown on a combination of glucose and GABA. Several alternative GABA transporters have been described in Agrobacterium tumefaciens and Rhizobium leguminosarum (Hosie et al. 2002; Planamente et al. 2010; White et al. 2008) that are distinct from the gabP lineage of GABA transporters and have homologs in DC3000 (Supplementary Table S1). Mutagenesis of these genes in the $\triangle g a b P$ background should give an indication of whether or not they are actively involved in GABA assimilation.

Once identified, it will be of interest to determine why GABA uptake and assimilation is observed in $\triangle g a b P$ when it is grown on glucose and GABA but not when bacteria are grown on GABA alone. Interestingly, recent work by Bren et al. (2016) has shown that, in E. coli, glucose is a suboptimal carbon source when bacteria are provided with glutamate rather than ammonia as a nitrogen source, as this combination of nutrient sources causes a metabolic imbalance in which levels of TCA cycle metabolites are high and levels of cAMP are low. The isotope dilution results presented here confirm that GABA is assimilated via the TCA cycle in $P$. syringae, which is consistent with previous studies describing the conversion of GABA by bacterial GABA transaminases to glutamate and succinate semialdehyde, through the transfer of an amino group from GABA to 2-oxoglutarate (Burnett et al. 1979; Prell et al. 2002). It will, therefore, be interesting to examine whether a similar metabolic imbalance occurs during co-metabolism of GABA and glucose in $P$. syringae and whether this is linked to regulation of this alternate transport mechanism.

\section{Concluding remarks.}

In conclusion, this study has established that PSPTO_5356 (GabP) is the primary GABA permease in DC3000, that it is likely to be regulated by the sigma factor RpoN, and that it functions in GABA-mediated suppression of virulence gene expression. It has also shown that, although GABA is the most abundant amino acid in the tomato apoplast, its uptake via GabP does not seem to be important for carbon and nitrogen acquisition by $P$. syringae during the early stages of plant colonization. In future work, it will be interesting to determine the identity of the one or more secondary GABA transporters used by DC3000 to transport GABA in the absence of $g a b P$, to investigate the mechanisms underpinning the regulation of $g a b P$ expression and GABA-dependent repression of $h r p$ expression and HR elicitation in $P$. syringae, and to fully elucidate the roles of apoplastic and intracellular GABA and GABA uptake in infection by DC3000.

\section{MATERIALS AND METHODS}

Bacterial strains and growth conditions.

The strains used in this study are described in Supplementary Table S2. Bacteria were stored at $-80^{\circ} \mathrm{C}$ in $20 \%$ glycerol, were grown overnight in Luria Bertani (LB) liquid media (Sambrook and Russell 2001), were collected by centrifugation, and were washed twice in the medium to be used in subsequent experiments, before adjusting to an $\mathrm{OD}$ at $600 \mathrm{~nm}\left(\mathrm{OD}_{600}\right)$ of 0.05 . For apoplast growth assays, bacteria were washed in $0.9 \% \mathrm{NaCl}$ prior to resuspension in apoplast extracts. For the GABA utilization assay, modified M9 media (Sambrook and Russell 2001) were used, in which $22 \mathrm{mM}$ glucose or $1.87 \mathrm{mM}$ ammonium were replaced by, or supplemented with, $22 \mathrm{mM}$ GABA. Bacteria were inoculated into 96-well plates, with a final volume of $150 \mu \mathrm{l}$ per well, and OD was measured using a Tecan Infinite 200 plate reader (Tecan, Theale, U.K.). Plates were incubated at $28^{\circ} \mathrm{C}$ for $48 \mathrm{~h}$, and $\mathrm{OD}_{600}$ readings were taken every $20 \mathrm{~min}$. Plates were shaken for $10 \mathrm{~s}$ before each reading.

\section{Plant species and cultivation.}

Five-week-old plants of Arabidopsis thaliana ecotype Ler and pop2-1 (Palanivelu et al. 2003) were used for the bacterial population assay and are described as wild-type and GABAoverexpressing Arabidopsis, respectively. Plants were grown under greenhouse conditions and were transferred to the laboratory 1 day before inoculation. Inoculated plants were maintained in the laboratory, with a light intensity of $40 \mu \mathrm{mol} \mathrm{m} \mathrm{s} \mathrm{s}^{-1}$ at $25^{\circ} \mathrm{C}$. Both Nicotiana tabacum L. cv. Delgold and N. tabacum L. cv. Xanthi were used in HR elicitation experiments. Seeds for N. tabacum L. cv. Delgold tobacco and $G A D \Delta \mathrm{C} 1$ tobacco lines (McLean et al. 2003) were provided by B. Shelp (University of Guelph, Canada). $N$. tabacum seeds were stored at $4{ }^{\circ} \mathrm{C}$ and were germinated by immersion in $0.5 \mathrm{mg}$ giberellic acid per milliliter overnight before planting in soil. Tomato (Solanum lycopersicum L. cv. Rio Grande) seeds were stored on dry filter paper (Whatman, 
Maidstone, U.K.) at room temperature and were germinated on wet filter paper for 3 days at $4^{\circ} \mathrm{C}$ in darkness before planting in soil. Seedlings were grown in Erin Excel multipurpose compost (Erin Horticulture, Hinxworth, U.K.) at $21^{\circ} \mathrm{C}$ with a $16-\mathrm{h}$ photoperiod and were watered three times a week. Six- to eightweek-old plants were used for leaf apoplast extractions and bacterial inoculations.

\section{Bioinformatic and phylogenetic analysis of Pseudomonas strains.}

Tools available via the Pseudomonas Genome Database were used to visualize PSPTO_5356 and the surrounding region (Winsor et al. 2011). Both fully and partially assembled Pseudomonas genomes present in GenBank (Benson et al. 2015) were used for phylogenetic analyses.

\section{Construction of the PSPTO_5356 (gabP) knockout mutant.}

PSPTO_5356 was deleted according to the protocol outlined by Park et al. (2010). Complementation of the $\Delta g a b P$ mutant was performed using the pBS46 broad-host range vector as described by Park et al. (2010). The primers used for construction of $\Delta g a b P$ and to amplify gabP from the genome of DC3000 to construct pBS46:gabP are listed in Supplementary Table S3.

\section{Carbon utilization analysis using Biolog GN2 MicroPlates.}

GN2 MicroPlates (Biolog, Hayward, CA, U.S.A.) were inoculated with bacteria suspended in inoculating fluid to an $\mathrm{OD}_{620}$ of 0.28 , according to the protocol described elsewhere (Rico and Preston 2008). The $\mathrm{pH}$ of the inoculating fluid was adjusted, using concentrated $\mathrm{HCl}$ to $\mathrm{pH} 7.0$ or $\mathrm{pH} 5.5$ prior to inoculation. Plates were incubated at $28^{\circ} \mathrm{C}$ for $36 \mathrm{~h}$. Spectrophotometric measurements $\left(\mathrm{OD}_{620}\right)$ were taken every $20 \mathrm{~min}$. The plates included a control well containing no carbon source. This well was used to determine the increase in OD that could be attributed to the use of endogenous carbon reserves by the bacteria. Data was corrected by subtracting the initial OD value of each individual well from all subsequent measurements to adjust for colored metabolites. Metabolic activity curves were integrated for the first $36 \mathrm{~h}$ of incubation to obtain summary values.

\section{qRT-PCR analysis of gene expression.}

Bacteria were harvested at an $\mathrm{OD}_{600}$ of 0.3 and $500 \mu \mathrm{l}$ of liquid culture was used for RNA extraction. RNA was extracted from cells using the RNeasy minikit (Qiagen, Crawley, U.K.), treated with DNase I (RNase-Free DNase set, Qiagen) and was then converted to cDNA using a cDNA synthesis kit (Bioline, London), according to the manufacturer's instructions. Primers were used to monitor the expression of PSPTO_5356 hrpL and avrE (using $r p o D$ and $g r o E L$ as reference genes). cDNA ( $7.5 \mu \mathrm{l})$ was added to each well, followed by $2.5 \mu \mathrm{l}$ of the forward and reverse primers and, then, $12.5 \mu$ l of SYBR Green master mix (Applied Biosystems, Foster City, CA, U.S.A.). Primer efficiency was measured using a dilution series of the pooled cDNA as a template to construct a standard curve and calculate amplification efficiency. An Applied Biosystems 7300 RealTime PCR machine was used and data was collected with the 7300 System SDS software (Applied Biosystems, Foster City, CA, U.S.A.). The following program was used: $50^{\circ} \mathrm{C}$ for $2 \mathrm{~min}, 95^{\circ} \mathrm{C}$ for $10 \mathrm{~min}$, and then, 40 cycles of $95^{\circ} \mathrm{C}$ for $15 \mathrm{~s}$, followed by $60^{\circ} \mathrm{C}$ for $1 \mathrm{~min}$.

\section{Tomato leaf apoplast extraction and bacterial growth assay.}

Tomato and tobacco leaf apoplast was extracted using the vacuum-infiltration method (O'Leary et al. 2014; Rico and Preston 2008). Leaf apoplast was lyophilized and reconstituted in distilled water at half the original volume, according to dilution calculations originally performed by Rico and Preston (2008). Bacterial cells were grown in LB medium overnight and were then washed in $0.9 \% \mathrm{wt} / \mathrm{vol} \mathrm{NaCl}$, prior to resuspension in apoplast extracts. The cells were inoculated into the reconstituted apoplast medium and growth was monitored spectrophotometrically as described for the bacterial growth assay conditions. Samples $(70 \mu \mathrm{l})$ were harvested at 0,8 , and $24 \mathrm{~h}$ and were centrifuged to remove bacterial cells. The apoplast supernatant was lyophilized again prior to ${ }^{1} \mathrm{H}-\mathrm{NMR}$ analysis.

\section{${ }^{1}$ H-NMR.}

Freeze-dried apoplast samples were reconstituted in $700 \mu \mathrm{l}$ of 80:20 $\mathrm{D}_{2} \mathrm{O} / \mathrm{CD}_{3} \mathrm{OD}$ containing $0.05 \%$ d4-trimethylsilylpropionate (d4-TSP). Samples were mixed thoroughly and were then allowed to stand and rehydrate for $45 \mathrm{~min}$. Samples were re-agitated to ensure the final sample was thoroughly mixed, and $600 \mu \mathrm{l}$ was transferred into a 5-mm glass NMR tube for NMR analysis. ${ }^{1} \mathrm{H}-\mathrm{NMR}$ data collection was carried out at $300 \mathrm{~K}$, using a Bruker Avance spectrometer (Bruker, Billerica, MA, U.S.A.) operating at $600 \mathrm{MHz}$, equipped with a 5-mm selective inverse probe. Spectra were collected using a water suppression pulse sequence with a relaxation delay of $5 \mathrm{~s}$. Each spectrum was acquired using 128 scans of 64,000 data points with a spectral width of $12 \mathrm{ppm}$. Spectra were automatically Fourier transformed, using an exponential window with a line broadening value of $0.5 \mathrm{~Hz}$. Phasing and baseline correction were carried out within the instrument software. ${ }^{1} \mathrm{H}$ chemical shifts were referenced to d4-TSP at $0.00 \mathrm{ppm}$.

Data for comparison plots was visualized in AMIX software (Bruker), and compounds were identified against a library of standards run under identical conditions. Metabolite trajectories were generated from the intensities of the corresponding NMR signals. Orthogonal signal correction was carried out prior to analysis, to remove systematic variation arising from differences in the quantity of bacteria in the independent experimental replicates (Wold et al. 1998).

\section{In planta growth assays and HR assays.}

Three-week-old tomato (Solanum lycopersicum cv. Moneymaker) plants were used for virulence assays. For observation of symptoms following syringae infiltration, leaves were infiltrated with a bacterial suspension of $3.52 \times 10^{4} \mathrm{CFU} / \mathrm{ml}$ in $10 \mathrm{mM}$ $\mathrm{MgCl}_{2}$ with a blunt syringe. Symptoms were photographed 7 days postinoculation. For observation of symptoms following dip inoculation, plants were inverted and the leaves were immersed for $30 \mathrm{~s}$ in a bacterial suspension of $10^{4}$ or $10^{6} \mathrm{CFU} / \mathrm{ml}$ in $10 \mathrm{mM}$ $\mathrm{MgCl}_{2}$ supplemented with $0.02 \%$ Silwet L-77. Leaves were allowed to dry and were scored and photographed 7 days postinoculation.

For in planta growth assays in tomato leaves, bacteria were resuspended in $10 \mathrm{mM} \mathrm{MgCl} 2$ at an $\mathrm{OD}_{600}$ of 0.1 , were diluted 1,000 -fold, and were inoculated by blunt syringe. Four replicate leaf disks were excised 0,2, and 5 days after inoculation and were individually homogenized in $1 \mathrm{ml}$ of $10 \mathrm{mM} \mathrm{MgCl}_{2}$. For in planta growth assays in A. thaliana leaves, bacteria were resuspended in $10 \mathrm{mM} \mathrm{MgCl}_{2}$ at an $\mathrm{OD}_{600}$ of 0.3 , were diluted at $10^{-4}$, and were inoculated by blunt syringe. Three replicate leaf disks were excised after 24, 48, and $78 \mathrm{~h}$ and were homogenized in $300 \mu \mathrm{l}$ of $10 \mathrm{mM} \mathrm{MgCl} 2$. The resulting homogenates were plated onto King's B agar containing $50 \mu \mathrm{g}$ of rifampicin per milliliter in serial 10-fold dilutions, to estimate the number of CFU per unit of leaf area. For HR assays, bacteria were suspended in $10 \mathrm{mM} \mathrm{MgCl}_{2}$ at an OD of 0.3 and were diluted to obtain inoculum densities of $3.52 \times 10^{8}$ and below. Suspensions were inoculated into tobacco leaves and the HR was recorded $24 \mathrm{~h}$ later. All experiments were repeated at least three times with similar results. 


\section{hrpL expression assays.}

The hrpL::luxCDABE reporter plasmid pBS63 (provided by B. Swingle, USDA-ARS) was electroporated into DC3000 and $\triangle g a b P$ and transformed cells were selected using $25 \mu \mathrm{g}$ of kanamycin per milliliter. Bacteria were cultured in black clearbottomed 96-well plates in which OD and luminescence were recorded using a Tecan Infinite 200 plate reader.

\section{Isotope dilution analysis of GABA uptake and metabolism.}

The uptake and metabolism of GABA by DC3000 and $\Delta g a b P$ was investigated using an isotope-dilution strategy in which cells were first grown on $99 \%\left[{ }^{13} \mathrm{C}_{6}\right]$ glucose until fully labeled with ${ }^{13} \mathrm{C}$, and were then transferred to a medium containing unlabeled GABA as either a carbon or nitrogen source. The subsequent depletion of label provided evidence for the metabolism of GABA. Bacteria were grown overnight in LB 10-ml cultures and were then collected by centrifugation and were resuspended in M9 containing $99 \%\left[{ }^{13} \mathrm{C}_{6}\right]$ glucose $(22 \mathrm{mM})$ at an $\mathrm{OD}_{600}$ of around 0.05 . The M9 cultures were again allowed to grow overnight until they reached a high density. The samples were centrifuged again, were resuspended in fresh labeled $\mathrm{M} 9$ at an $\mathrm{OD}_{600}$ of 0.05 , and were allowed to grow to an $\mathrm{OD}_{600}$ of 0.3 (by this stage, the specific ${ }^{13} \mathrm{C}$ abundance of $\mathrm{C}$ atoms in amino acids was greater than $95 \%$ ). Bacteria were resuspended in $10 \mathrm{ml}$ of modified M9 media containing $22 \mathrm{mM}$ GABA as either a carbon, nitrogen, or carbon and nitrogen source, with unmodified M9 used as a control. Aliquots $(1 \mathrm{ml})$ of cells were removed at $0,2,4,6$, and $8 \mathrm{~h}$ for analysis, and at $24 \mathrm{~h}$, the remaining culture was harvested. Bacteria were collected by centrifugation and were washed once, using $1 \times \mathrm{M} 9$ salts, and pellets stored at $-80^{\circ} \mathrm{C}$.

\section{Gas chromatography-mass spectrometry (GC-MS) analysis of the constituent amino acids of protein.}

Protein in bacterial samples was hydrolyzed in $6 \mathrm{M} \mathrm{HCl}$ and the resulting amino acids were converted to their tert-butyldimethylsilyl derivatives, using MTBSTFA containing 1\% TBDMS (SigmaAldrich, Gillingham, U.K.) in pyridine as described by Zamboni et al. (2009). Derivatized amino acids were then analyzed by GCMS on an Agilent 7890A GC coupled to an Agilent 5975C quadrupole MS, using procedures described elsewhere (Masakapalli et al. 2013; Williams et al. 2010). Ion chromatograms were baseline corrected using MetAlign (Lommen 2009) and peaks were identified using AMDIS32 (National Institute of Standards and Technology) and a library of TBDMS-derivatized amino acids generated in our laboratory. Mass isotopomer abundances were quantified using Chemstation, and the fractional abundance of ${ }^{13} \mathrm{C}$-labeled amino acids was determined after correction for the presence of naturally occurring heavy isotopes in the derivatized fragments (Wahl et al. 2004).

\section{High-pressure liquid chromatography (HPLC) analysis of soluble amino acids in $N$. tabacum apoplast extracts.}

Apoplast samples were obtained from two leaves of two replicate plants, for each tobacco line. Apoplast $(10 \mu \mathrm{l})$ was mixed with $10 \mu \mathrm{l}$ of $0.1 \mathrm{M} \mathrm{HCl}, 5 \mu \mathrm{l}$ of $0.52 \mathrm{M} \mathrm{N}$-isobutyryl-D-cysteine, $5 \mu \mathrm{l}$ of $0.32 \mathrm{M} o$-phthaldialdehyde and $55 \mu \mathrm{l}$ of $0.13 \mathrm{M}$ borate buffer, $\mathrm{pH}$ 10.4. This mixture was incubated for $2 \mathrm{~min}$ at room temperature and $80 \mu \mathrm{l}$ was injected into a HPLC reverse phase $\mathrm{C}-18$ column. The HPLC program used was as follows: 0 to $80 \%$ buffer B for $80 \mathrm{~min}, 80$ to $100 \%$ buffer B for $10 \mathrm{~min}$, and 100

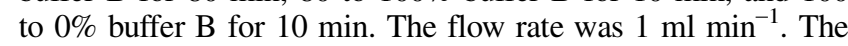
relative percentages of buffer $\mathrm{B}$ were achieved by altering the flow of this buffer with respect to buffer A. Buffer A consisted of $23 \mathrm{mM}$ sodium acetate trihydrate and 10\% HPLC grade methanol. Buffer B consisted of $23 \mathrm{mM}$ sodium acetate trihydrate and $60 \%$ HPLC grade methanol. The fluorescence detector was set at $230 \mathrm{~nm}$ excitation and $445 \mathrm{~nm}$ emission. Internal standards of
$10 \mathrm{mM} \mathrm{GABA}$ and amino acids were run on the column to establish the position of individual amino acids in the HPLC profile. Amino acid abundance was calculated from the peak area.

\section{ACKNOWLEDGMENTS}

This research was supported by a Magdalen College Scholarship awarded to S. L. McCraw; by funding from the Biotechnology and Biological Sciences Research Council (BB/E007872/1) awarded to G. M. Preston, and by a grant from the Basic Science Research Program of the National Research Foundation of Korea funded by the Ministry of Education (NRF-2013R1A1A2062953) to D. H. Park. We are grateful to B. Shelp (University of Guelph) for providing tobacco lines, A. Chatterjee (University of Missouri) for providing an rpoN mutant of DC3000, and B. Swingle (Cornell University) for providing plasmids. We thank L. Miguet for assistance with HPLC analyses. Data associated with this manuscript has been deposited in the Oxford University Research Archive under DOI: 10.5287/bodleian:wxZzBaKXd.

\section{LITERATURE CITED}

Allan, W. L., and Shelp, B. J. 2006. Fluctuations of $\gamma$-aminobutyrate, $\gamma$-hydroxybutyrate, and related amino acids in Arabidopsis leaves as a function of the light-dark cycle, leaf age, and N stress. Can. J. Bot. 84: 1339-1346.

Ashihara, H., Ludwig, I. A., Katahira, R., Yokota, T., Fujimura, T., and Crozier, A. 2015. Trigonelline and related nicotinic acid metabolites: Occurrence, biosynthesis, taxonomic considerations, and their roles in planta and in human health. Phytochem. Rev. 14:765-798.

Badel, J. L., Shimizu, R., Oh, H.-S., and Collmer, A. 2006. A Pseudomonas syringae pv. tomato avrE1/hopM1 mutant is severely reduced in growth and lesion formation in tomato. Mol. Plant-Microbe Interact. 19:99-111.

Benson, D. A., Clark, K., Karsch-Mizrachi, I., Lipman, D. J., Ostell, J., and Sayers, E. W. 2015. GenBank. Nucleic Acids Res. 43:D30-D35.

Beuvé, N., Rispail, N., Laine, P., Cliquet, J. B., Ourry, A., and Le Deunff, E. 2004. Putative role of $\gamma$-aminobutyric acid as a long distance signal in up-regulation of nitrate uptake in Brassica napus L. Plant Cell Environ. 27:1035-1046.

Bouche, N., Lacombe, B., and Fromm, H. 2003. GABA signalling: A conserved and ubiquitous mechanism. Trends Cell Biol. 13:607-610.

Brechtel, C. E., and King, S. C. 1998. 4-aminobutyrate (GABA) transporters from the amine-polyamine-choline superfamily: Substrate specificity and ligand recognition profile of the 4-aminobutyrate permease from Bacillus subtilis. Biochem. J. 333:565-571.

Brechtel, C. E., Hu, L., and King, S. C. 1996. Substrate specificity of the Escherichia coli 4-aminobutyrate carrier encoded by gabP. J. Biol. Chem. 271:783-788.

Breitkreuz, K. E., Shelp, B. J., Fischer, W. N., Schwacke, R., and Rentsch, D. 1999. Identification and characterization of GABA, proline and quaternary ammonium compound transporters from Arabidopsis thaliana. FEBS Lett. 450:280-284.

Bren, A., Park, J. O., Towbin, B. D., Dekel, E., Rabinowitz, J. D., and Alon, U. 2016. Glucose becomes one of the worst carbon sources for E.coli on poor nitrogen sources due to suboptimal levels of cAMP. Sci. Rep. 6:24834.

Brencic, A., and Winans, S. C. 2005. Detection of and response to signals involved in host-microbe interactions by plant-associated bacteria Microbiol. Mol. Biol. Rev. 69:155-194.

Buell, C. E., Joardar, V., Lindeberg, M., Selengut, J., Paulsen, I. T., Gwinn, M. L., Dodson, R. J., Deboy, R. T., Durkin, A. S., Kolonay, J. F., Madupu, R., Daugherty, S., Brinkac, L., Beanan, M. J., Haft, D. H., Nelson, W. C., Davidsen, T., Zafar, N., Zhou, L., Liu, J., Yuan, Q., Khouri, H., Fedorova, N., Tran, B., Russell, D., Berry, K., Utterback, T., Van Aken, S. E., Feldblyum, T. V., D’Ascenzo, M., Deng, W. L., Ramos, A. R., Alfano, J. R., Cartinhour, S., Chatterjee, A. K., Delaney, T. P., Lazarowitz, S. G., Martin, G. B., Schneider, D. J., Tang, X., Bender, C. L., White, O., Fraser, C. M., and Collmer, A. 2003. The complete genome sequence of the Arabidopsis and tomato pathogen Pseudomonas syringae pv. tomato DC3000. Proc. Natl. Acad. Sci. U.S.A. 100:10181-10186.

Burnett G, Walsh C, Yonaha K, Toyama S and Soda K. 1979. Stereospecificity of enzymatic transamination of [gamma]-aminobutyrate. J. Chem. Soc. Chem. Comm. 19:826-828.

Chatnaparat, T., Li, Z., Korban, S. S., and Zhao, Y. 2015a. The bacterial alarmone (p)ppGpp is required for virulence and controls cell size and survival of Pseudomonas syringae on plants. Environ. Microbiol. 17: 4253-4270.

Chatnaparat, T., Li, Z., Korban, S. S., and Zhao, Y. 2015b. The stringent response mediated by (p)ppGpp is required for virulence of Pseudomonas syringae pv. tomato and its survival on tomato. Mol. Plant-Microbe Interact. 28:776-789. 
Chen, C., and Beattie, G. A. 2007. Characterization of the osmoprotectant transporter OpuC from Pseudomonas syringae and demonstration that cystathionine- $\beta$-synthase domains are required for its osmoregulatory function. J. Bacteriol. 189:6901-6912.

Ferson, A. E., Wray, L. V., and Fisher, S. H. 1996. Expression of the Bacillus subtilis gabP gene is regulated independently in response to nitrogen and amino acid availability. Mol. Microbiol. 22:693-701.

Freeman, B. C., Chen, C., and Beattie, G. A. 2010. Identification of the trehalose biosynthetic loci of Pseudomonas syringae and their contribution to fitness in the phyllosphere. Environ. Microbiol. 12:1486-1497.

Freeman, B. C., Chen, C., Yu, X., Nielsen, L., Peterson, K., and Beattie, G. A. 2013. Physiological and transcriptional responses to osmotic stress of two Pseudomonas syringae strains that differ in epiphytic fitness and osmotolerance. J. Bacteriol. 195:4742-4752.

Girousse, C., Bonnemain, J. L., Delrot, S., and Bournoville, R. 1991. Sugar and amino acid composition of phloem sap of Medicago sativa: A comparative study of two collecting methods. Plant Physiol. Biochem. 29:41-48.

Grallath, S., Weimar, T., Meyer, A., Gumy, C., Suter-Grotemeyer, M., Neuhaus, J. M., and Rentsch, D. 2005. The AtProT family. Compatible solute transporters with similar substrate specificity but differential expression patterns. Plant Physiol. 137:117-126.

Gupta, K. J., Brotman, Y., Segu, S., Zeier, T., Zeier, J., Persijn, S. T., Cristescu, S. M., Harren, F. J. M., Bauwe, H., Fernie, A. R., Kaiser, W. M., and Mur, L. A. J. 2013. The form of nitrogen nutrition affects resistance against Pseudomonas syringae pv. phaseolicola in tobacco. J. Exp. Bot. 64:553-568.

Hendrickson, E. L., Guevera, P., and Ausubel, F. M. 2000a. The alternative sigma factor RpoN is required for hrp activity in Pseudomonas syringae pv. maculicola and acts at the level of $h r p L$ transcription. J. Bacteriol. 182:3508-3516.

Hendrickson, E. L., Guevera, P., Penaloza-Vàzquez, A., Shao, J., Bender, C., and Ausubel, F. M. 2000b. Virulence of the phytopathogen Pseudomonas syringae pv. maculicola is rpoN dependent. J. Bacteriol. 182:3498-3507.

Hernández-Morales, A., De la Torre-Zavala, S., Ibarra-Laclette, E., Hernández-Flores, J. L., Jofre-Garfias, A. E., Martínez-Antonio, A., and Álvarez-Morales, A. 2009. Transcriptional profile of Pseudomonas syringae pv. phaseolicola NPS3121 in response to tissue extracts from a susceptible Phaseolus vulgaris L. cultivar. BMC Microbiol. 9:257-273.

Hosie, A. H. F., Allaway, D., Galloway, C. S., Dunsby, H. A., and Poole, P. S. 2002. Rhizobium leguminosarum has a second general amino acid permease with unusually broad substrate specificity and high similarity to branched-chain amino acid transporters (Bra/ LIV) of the ABC family. J. Bacteriol. 184:4071-4080.

Hossain, S. J., Aoshima, H., Koda, H., and Kiso, Y. 2003. Effects of coffee components on the response of $\mathrm{GABA}(\mathrm{A})$ receptors expressed in Xenopus oocytes. J. Agric. Food Chem 51:7568-7575.

Huynh, T., Dahlbeck, D., and Staskawicz, B. 1989. Bacterial blight of soybean: Regulation of a pathogen gene determining host cultivar specificity. Science 245:1374-1377.

Jauniaux, J. C., Vandenbol, M., Vissers, S., Broman, K., and Grenson, M. 1987. Nitrogen catabolite regulation of proline permease in Saccharomyces cerevisiae. Cloning of the PUT4 gene and study of PUT4 RNA levels in wild-type and mutant strains. Eur. J. Biochem. 164:601-606.

Jones, J., Studholme, D. J., Knight, C. G., and Preston, G. M. 2007. Integrated bioinformatic and phenotypic analysis of RpoN-dependent traits in the plant growth-promoting bacterium Pseudomonas fluorescens SBW25. Environ. Microbiol. 9:3046-3064.

Jovanovic, M., Lawton, E., Schumacher, J., and Buck, M. 2014. Interplay among Pseudomonas syringae HrpR, HrpS and HrpV proteins for regulation of the type III secretion system. FEMS Microbiol. Lett. 356: 201-211.

Kvitko, B. H., Ramos, A. R., Morello, J. E., Oh, H. S., and Collmer, A. 2007. Identification of harpins in Pseudomonas syringae pv. tomato DC3000, which are functionally similar to $\mathrm{HrpK} 1$ in promoting translocation of type III secretion system effectors. J. Bacteriol. 189:8059-8072.

Lommen, A. 2009. Metalign: Interface-driven, versatile metabolomics tool for hyphenated full-scan mass spectrometry data preprocessing. Anal. Chem. 81:3079-3086.

Masakapalli, S. K., Kruger, N. J., and Ratcliffe, R. G. 2013. The metabolic flux phenotype of heterotrophic Arabidopsis cells reveals a complex response to changes in nitrogen supply. Plant J. 74:569-582.

Masclaux, C., Valadier, M. H., Brugière, N., Morot-Gaudry, J. F., and Hirel, B. 2000. Characterization of the sink/source transition in tobacco (Nicotiana tabacum L.) shoots in relation to nitrogen management and leaf senescence. Planta 211:510-518.

McLean, M. D., Yevtushenko, D. P., Deschene, A., Van Cauwenberghe, O. R., Makhmoudova, A., Potter, J. W., Bown, A. W., and Shelp, B. J.
2003. Overexpression of glutamate decarboxylase in transgenic tobacco plants confers resistance to the northern root-knot nematode. Mol. Breed. 11:277-285.

Metzner, M., Germer, J., and Hengge, R. 2004. Multiple stress signal integration in the regulation of the complex $\sigma^{\mathrm{s}}$-dependent $c s i D-y g a F$ gabDTP operon in Escherichia coli. Mol. Microbiol. 51:799-811.

Minorsky, P. V. 2002. Trigonelline: A diverse regulator in plants. Plant Physiol. 128:7-8.

O’Leary, B. M., Rico, A., McCraw, S., Fones, H. N., and Preston, G. M 2014. The infiltration-centrifugation technique for extraction of apoplastic fluid from plant leaves using Phaseolus vulgaris as an example. J. Vis. Exp. 94:52113.

O’Leary, B. M., Neale, H. C., Geilfus, C. M., Jackson, R. W., Arnold, D. L. and Preston, G. M. 2016. Early changes in apoplast composition associated with defence and disease in interactions between Phaseolus vulgaris and the halo blight pathogen Pseudomonas syringae pv. phaseolicola. Plant Cell Environ. 39:2172-2184.

Ortiz-Martín, I., Thwaites, R., Mansfield, J. W., and Beuzón, C. R. 2010. Negative regulation of the Hrp type III secretion system in Pseudomonas syringae pv. phaseolicola. Mol. Plant-Microbe Interact. 23:682-701.

Palanivelu, R., Brass, L., Edlund, A. F., and Preuss, D. 2003. Pollen tube growth and guidance is regulated by POP2, an Arabidopsis gene that controls GABA levels. Cell 114:47-59.

Park, D., Mirabella, R., Bronstein, P. A., Preston, G. M., Haring, M. A., Lim, C. K., Collmer, A., and Schuurink, R. C. 2010. Mutations in $\gamma$-aminobutyric acid (GABA) transaminase genes in plants or Pseudomonas syringae reduce bacterial virulence. Plant J. 64:318-330.

Planamente, S., Vigouroux, A., Mondy, S., Nicaise, M., Faure, D., and Moréra, S. 2010. A conserved mechanism of GABA binding and antagonism is revealed by a structure-function analysis of the periplasmic binding protein Atu2422 in Agrobacterium tumefaciens. J. Biol. Chem. 285:30294-30303.

Prell, J., Boesten, B., Poole, P., and Priefer, U. B. 2002. The Rhizobium leguminosarum bv. viciae VF39 $\gamma$-aminobutyrate (GABA) aminotransferase gene $(g a b T)$ is induced by GABA and highly expressed in bacteroids. Microbiology 148:615-623.

Rahme, L. G., Mindrinos, M. N., and Panopoulos, N. J. 1992. Plant and environmental sensory signals control the expression of hrp genes in Pseudomonas syringae pv. phaseolicola. J. Bacteriol. 174:3499-3507.

Ramos, L. S., Lehman, B. L., Sinn, J. P., Pfeufer, E. E., Halbrendt, N. O., and McNellis, T. W. 2013. The fire blight pathogen Erwinia amylovora requires the rpoN gene for pathogenicity in apple. Mol. Plant Pathol. 14:838-843.

Rico, A., and Preston, G. M. 2008. Pseudomonas syringae pv. tomato DC3000 uses constitutive and apoplast-induced nutrient assimilation pathways to catabolize nutrients that are abundant in the tomato apoplast. Mol. Plant-Microbe Interact. 21:269-282.

Sambrook, J., and Russell, D. W. 2001. Molecular Cloning: A Laboratory Manual. Cold Spring Harbor Laboratory Press, Cold Spring Harbor, NY, U.S.A.

Schneider, B. L., Ruback, S., Kiupakis, A. K., Kasbarian, H., Pybus, C., and Reitzer, L. 2002. The Escherichia coli gabDTPC operon: Specific $\gamma$-aminobutyrate catabolism and nonspecific induction. J. Bacteriol. 184: 6976-6986.

Solomon, P. S., and Oliver, R. P. 2001. The nitrogen content of the tomato leaf apoplast increases during infection by Cladosporium fulvum. Planta 213:241-249.

Studholme, D. J., Buck, M., and Nixon, B. T. 2000. Identification of potential $\sigma^{\mathrm{N}}$-dependent promoters in bacterial genomes. Microbiology 146:3021-3023.

Sulieman, S., and Schulze, J. 2010. Phloem-delivered $\gamma$-aminobutyric acid (GABA) is involved in upregulating nodule $\mathrm{N}_{2}$ fixation efficiency in the model legume Medicago truncatula. Plant Cell Environ. 33:2162-2172.

Tang, X., Xiao, Y., and Zhou, J. M. 2006. Regulation of the type III secretion system in phytopathogen bacteria. Mol. Plant-Microbe Interact. 19:1159-1166.

Thwaites, R., Spanu, P. D., Panopoulos, N. J., Stevens, C., and Mansfield, J. W. 2004. Transcriptional regulation of components of the type III secretion system and effectors in Pseudomonas syringae pv. phaseolicola. Mol. Plant-Microbe Interact. 17:1250-1258.

Wahl, S. A., Dauner, M., and Wiechert, W. 2004. New tools for mass isotopomer data evaluation in ${ }^{13} \mathrm{C}$ flux analysis: Mass isotope correction, data consistency checking, and precursor relationships. Biotechnol. Bioeng. 85:259-268.

Ward, J. L., Forcat, S., Beckmann, M., Bennett, M., Miller, S. J., Baker, J. M., Hawkins, N. D., Vermeer, C. P., Lu, C., Lin, W., Truman, W. M., Beale, M. H., Draper, J., Mansfield, J. W., and Grant, M. 2010. The metabolic transition during disease following infection of 
Arabidopsis thaliana by Pseudomonas syringae pv. tomato. Plant J. 63:443-457.

Wei, H. L., and Collmer, A. 2012. Multiple lessons from the multiple functions of a regulator of type III secretion system assembly in the plant pathogen Pseudomonas syringae. Mol. Microbiol. 85:195-200.

White, J. P., Prell, J., Ramachandran, V. K., and Poole, P. S. 2008. Characterisation of a $\gamma$-aminobutyric acid transport system of Rhizobium leguminosarum bv. viciae 3841. J. Bacteriol. 191:1547-1555.

Williams, T. C. R., Poolman, M. G., Howden, A. J. M., Schwarzlander, M., Fell, D. A., Ratcliffe, R. G., and Sweetlove, L. J. 2010. A genome-scale metabolic model accurately predicts fluxes in central metabolism under stress conditions. Plant Physiol. 154:311-323.

Winsor, G. L., Lam, D. K. W., Fleming, L., Lo, R., Whiteside, M. D., Yu, N. Y., Hancock, R. E. W., and Brinkman, F. S. L. 2011. Pseudomonas genome database: Improved comparative analysis and population genomics capability for Pseudomonas genomes. Nucleic Acids Res. 39:D596-D600.

Wold, S., Antti, H., Lindgren, F., and Ohman, J. 1998. Orthogonal signal correction of near-infrared spectra. Chemom. Intell. Lab. Syst. 44: 175-185.

Wright, C. A., and Beattie, G. A. 2004. Pseudomonas syringae pv. tomato cells encounter inhibitory levels of water stress during the hypersensitive response of Arabidopsis thaliana. Proc. Natl. Acad. Sci. U.S.A. 101: 3269-3274.
Yang, H. J., Lee, J. S., Cha, J. Y., and Baik, H. S. 2011. Negative regulation of pathogenesis in Pseudomonas syringae pv. tabaci 11528 by ATPdependent lon protease. Mol. Cells 32:317-323.

Yu, X., Lund, S. P., Scott, R. A., Greenwald, J. W., Records, A. H., Nettleton, D., Lindow, S. E., Gross, D. C., and Beattie, G. A. 2013 Transcriptional responses of Pseudomonas syringae to growth in epiphytic versus apoplastic leaf sites. Proc. Natl. Acad. Sci. U.S.A. 110:E425-E434.

Yu, X., Lund, S. P., Greenwald, J. W., Records, A. H., Scott, R. A., Nettleton, D., Lindow, S. E., Gross, D. C., and Beattie, G. A. 2014 Transcriptional analysis of the global regulatory networks active in Pseudomonas syringae during leaf colonization. MBio 5:e01683-14.

Zamboni, N., Fendt, S. M., Rühl, M., and Sauer, U. 2009. ${ }^{13}$ C-based metabolic flux analysis. Nat. Protoc. 4:878-892.

Zaprasis, A., Hoffmann, T., Stannek, L., Gunka, K., Commichau, F. M., and Bremer, E. 2014. The $\gamma$-aminobutyrate permease GabP serves as the third proline transporter of Bacillus subtilis. J. Bacteriol. 196:515-526.

Zhang, X. X., and Rainey, P. B. 2008. Dual involvement of CbrAB and NtrBC in the regulation of histidine utilization in Pseudomonas fluorescens SBW25. Genetics 178:185-195.

Zhao, Z., Ding, J. Y., Ma, W. H., Zhou, N. Y., and Liu, S. J. 2012. Identification and characterization of $\gamma$-aminobutyric acid uptake system $\mathrm{GabP}_{C g}(\mathrm{NVg10464)}$ in Corynebacterium glutamicum. Appl. Environ. Microbiol. 78:2596-2601. 